\title{
EXPERIMENTAL ANALYSIS OF THE FATIGUE LIFE OF THREADED PIPE CONNECTIONS UNDER CYCLIC BENDING
}

\author{
J. Van Wittenberghe ${ }^{1}$, T. Galle ${ }^{1}$, W. De Waele ${ }^{1}$ and P. De Baets ${ }^{1}$ \\ ${ }^{1}$ Ghent University, Laboratory Soete, Belgium
}

\begin{abstract}
When subjected to cyclic loads, fatigue cracks can cause failure of pipe systems joined by threaded pipe connections. In this study, the effect of contact conditions and coupling geometry is investigated experimentally. Fatigue tests under cyclic bending are carried out on three different threaded connection configurations. The resulting fatigue lives are compared and fracture surfaces are investigated. The fatigue cracks are found to initiate at the last engaged thread of the pin and fatigue life can be increased by applying PTFE tape or changing the coupling geometry.
\end{abstract}

Keywords: threaded pipe connection; threaded pipe coupling; fatigue; cyclic bending; experiment.

\section{INTRODUCTION}

Threaded pipe connections are used in the oil and gas industry in particular to connect casing strings, drill pipe strings or production risers and pipelines. In order to maintain a sealed and secure connection while in service, the connections are generally preloaded. To introduce this preload, the connections have tapered threads and they are assembled by applying a certain make-up torque. The combination of the make-up torque and external loads results in a multiaxial stress distribution over the coupling, where the coupling's threads act as stress raisers. When used in offshore environments, waves and currents cause dynamic loads acting on the pipelines. The pipe connections remain the weakest points because fatigue cracks can initiate in the connection's threads [1,2]. As shown previously by the authors [3], the fatigue life of threaded pipe connections is affected by the global connection geometry and local conditions as thread shape, preload and thread contact. In this paper the contribution of a selection of these different aspects is investigated.

\section{EXPERIMENTAL TEST PROGRAM}

The cyclic bending experiments are carried out on the four-point bending fatigue setup described in [2]. Three different connection types are tested. First, the standard 1" API Line Pipe connection is tested. Then a standard API Line Pipe configuration is tested, where prior to the make up PTFE tape (Teflon) was applied to the threads. Finally, an additional configuration is tested, derived from the standard API Line Pipe type, with a reduced coupling wall thickness (see Figure 1).

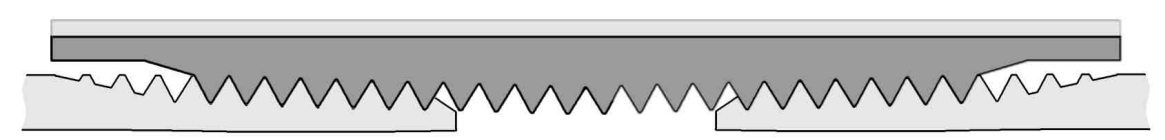

Figure 1: Section view of a Modified API Line Pipe connection with reduced box wall.

\subsection{Standard 1" API Line Pipe}

\subsubsection{S-N curve}

In total 15 tests are conducted on standard 1" API Line Pipe specimens, 13 of which failed due to a fatigue crack. The other two specimens did not fail and the test was stopped after exceeding 2 million cycles. Each test is represented by a single data point in the S-N plot of Figure 2. The number of cycles to failure $N$ is shown together with the applied gross bending stress amplitude $S_{a}$. This is the amplitude of the maximum bending stress in the pipe material without taking into account the stress concentrations of the threads.

The data is processed according the BS 7608 fatigue standard [4], in which a fatigue limit is assumed at 2 million cycles. The fatigue data is expected to follow a Basquin relation written in the form of Eq. (1). 


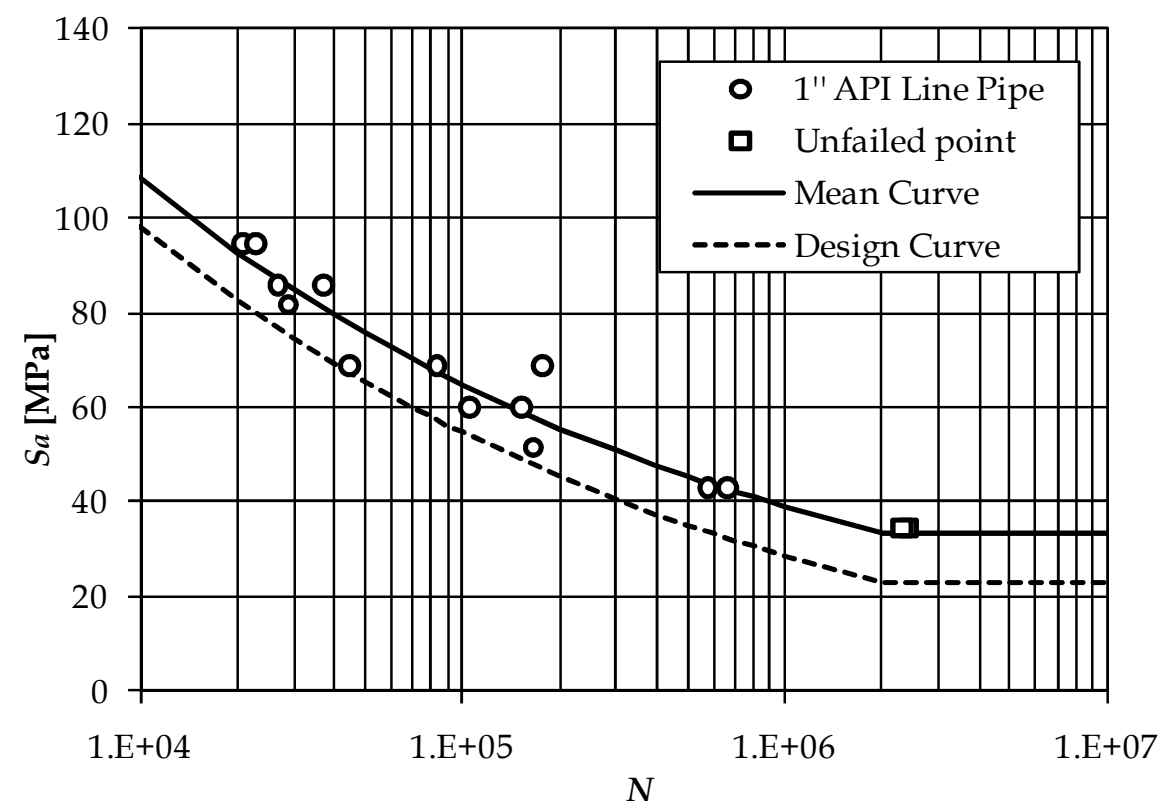

Figure 2: S-N curve for the standard 1" API Line Pipe connection (load ratio $R=0.1$ ).

$$
S_{a}=A \cdot N^{-B}
$$

The factors $A$ and $B$ of this mean curve are found by regression analysis of the data points of the tests for which a leak occurred. The best least-squares fit of the mean curve to the data points has a standard deviation $S T D=5.14 \mathrm{MPa}$ and is given by Eq. (2). The design curve shown in Figure 2 is calculated as the mean curve minus two times the standard deviation. Hence, the design curve is associated with a $95.4 \%$ probability of survival.

$$
S_{a}=848.7 \cdot N^{-0.2233}
$$

\subsubsection{Fracture surface analysis}

For the standard 1" API Line Pipe connection a detailed analysis is made of the fracture surface to get a better understanding of the fatigue crack growth behaviour of the connection. To do this, either longitudinal or transverse sections were made by cutting the specimen or by forcing brittle fracture of the pin after cooling the samples in liquid air to a temperature of about $-180^{\circ} \mathrm{C}$. All observed cracks appear at the last fully engaged thread of the pin as illustrated in the section view in Figure 3 . The crack is indicated by the arrow and is oriented perpendicular to the cutting surface. The root of the last engaged thread or $L E T$ of the pin is the expected location for the cracks to initiate, since it corresponds to the location where the highest stress concentrations occur [2]. In the fracture surface shown in Figure 4, the shape of the fatigue crack for a test with stress amplitude $S_{a}=94.5 \mathrm{MPa}$ is shown. From the figure it can be seen that the fatigue crack initiated along the root of the LET and propagated through the wall of the pin. While doing this, the crack propagated over a wide segment of the circumference. When the remaining wall thickness became insufficient to withstand the applied stress, a ductile overload fracture occurred, creating a throughthickness crack. Since continuous leak detection is used during the experiments, the test is automatically stopped after this. In several cases the ductile overload is much smaller or negligible, but the global shape of the entire fatigue crack is comparable for all observed fracture surfaces.

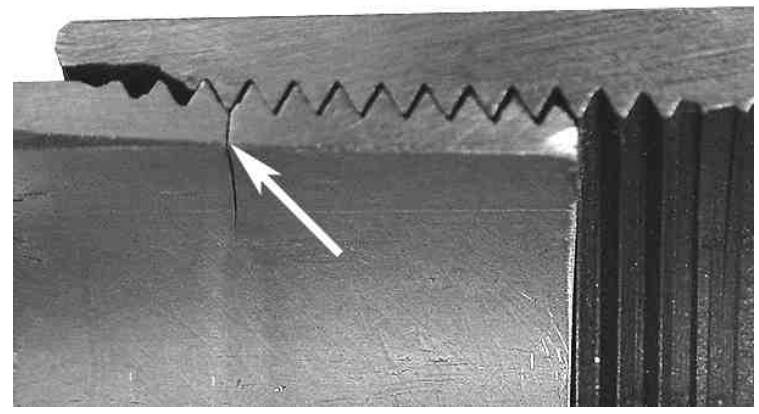

Figure 3: Fatigue crack initiated at the LET of the pin of a standard 1" API Line Pipe specimen. 


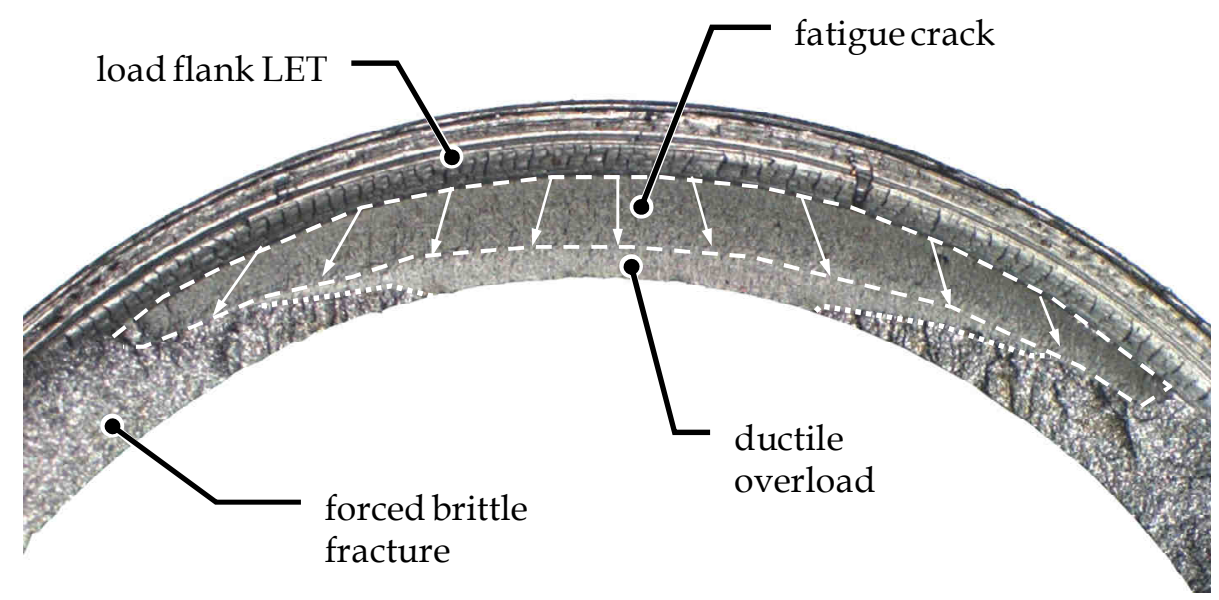

Figure 4: Fracture surface of a fatigue crack in a standard 1" API Line Pipe specimen.

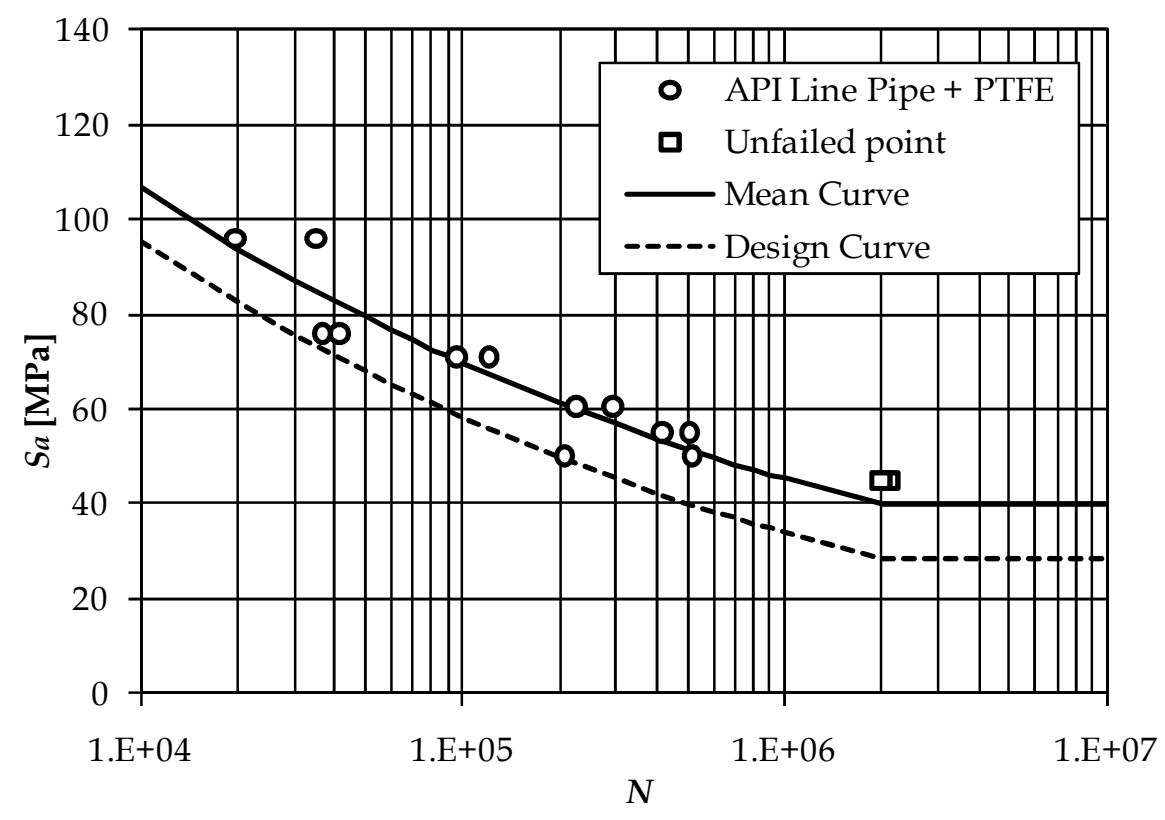

Figure 5: S-N curve for the 1" API Line Pipe connection with PTFE $(R=0.1)$.

\subsection{Standard 1" API Line Pipe with PTFE tape}

\subsubsection{S-N curve}

Fourteen tests are carried out on standard 1" API Line Pipe connections with PTFE between the threads, of which 2 did not fail after 2 million cycles. The test results together with the mean and design curves corresponding to the data are shown in Figure 5. The mean curve has a standard deviation of $5.74 \mathrm{MPa}$ compared to the measured data and is described by the following relation.

$$
S_{a}=597.2 \cdot N^{-0.1866}
$$

\subsubsection{Fracture surface}

The fracture surface for a fatigue test with a stress amplitude of $S_{a}=90 \mathrm{MPa}$ is shown in Figure 6. A leak appeared in the specimen after 35220 cycles. In order to quantify the fatigue crack growth, this surface is investigated using scanning electron microscopy or SEM. With this microscopic technique, magnification factors of several thousands can be achieved and individual fatigue striations can visualised. Hence cyclic crack depth increments can be measured. This was done at the three locations indicated in Figure 6. Location 1 is near the thread root where the fatigue crack initiated. Location 2 is near the inside wall of the pin and location 3 is at the border between the fatigue crack and the forced brittle fracture zone. 


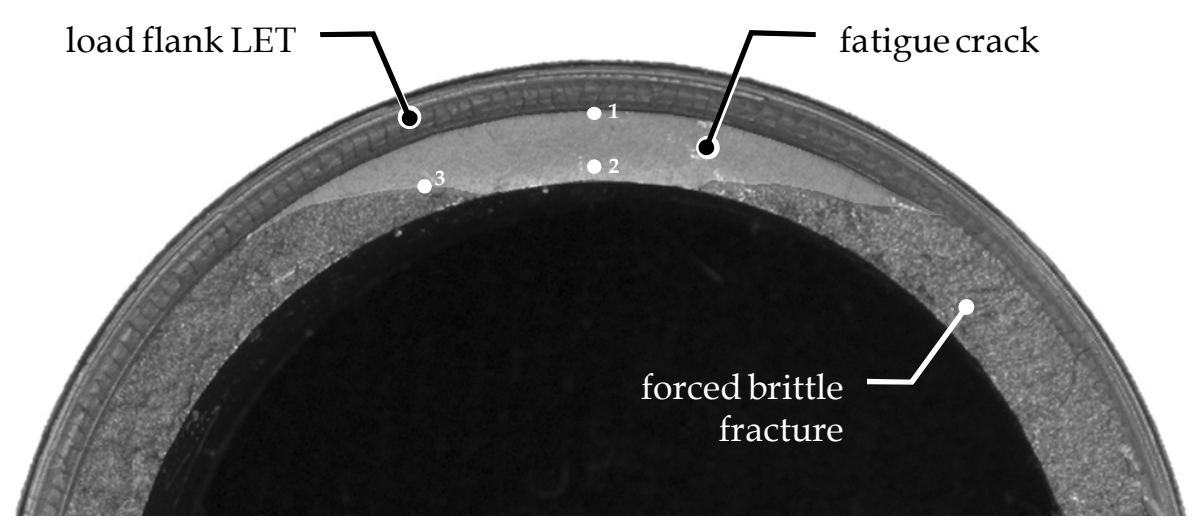

Figure 6: Fracture surface of a 1" API Line Pipe specimen with PTFE.

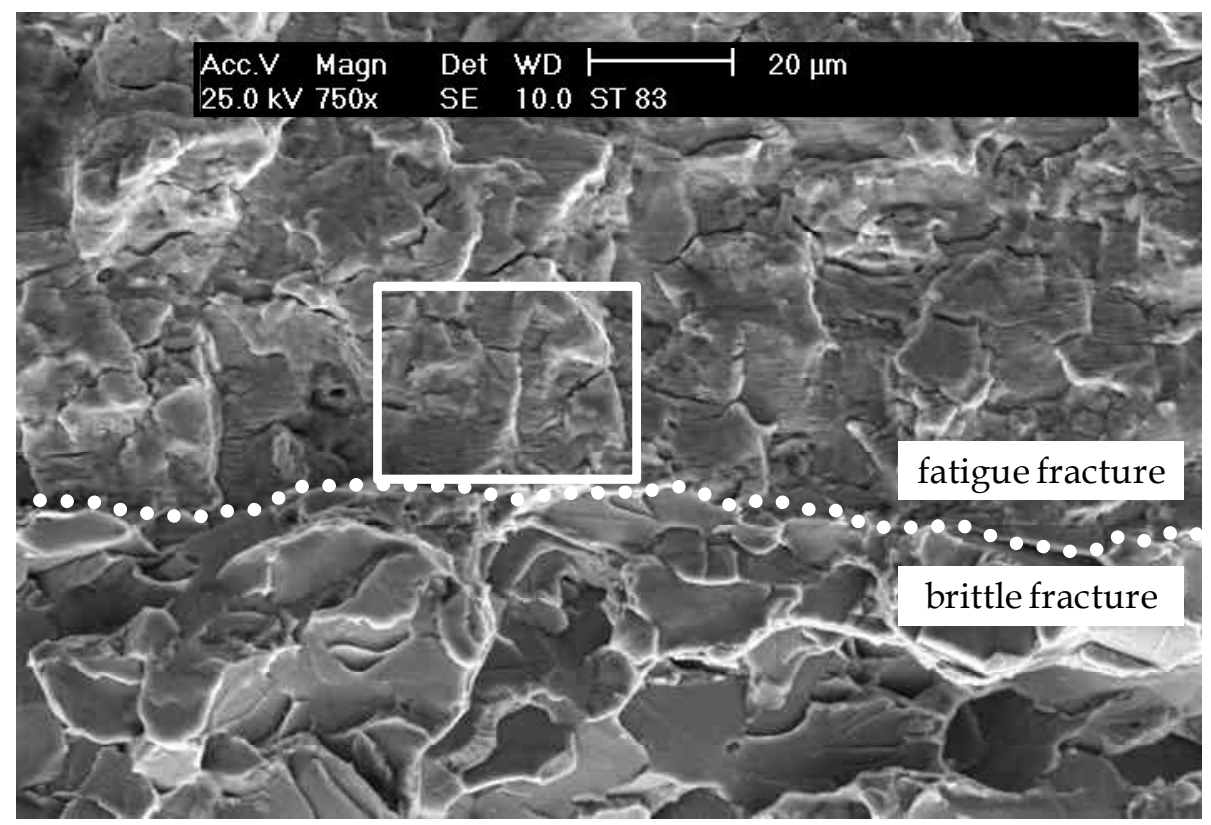

Figure 7: SEM micrograph of the boundary between the fatigue crack and the forced brittle fracture (magnification 750x).

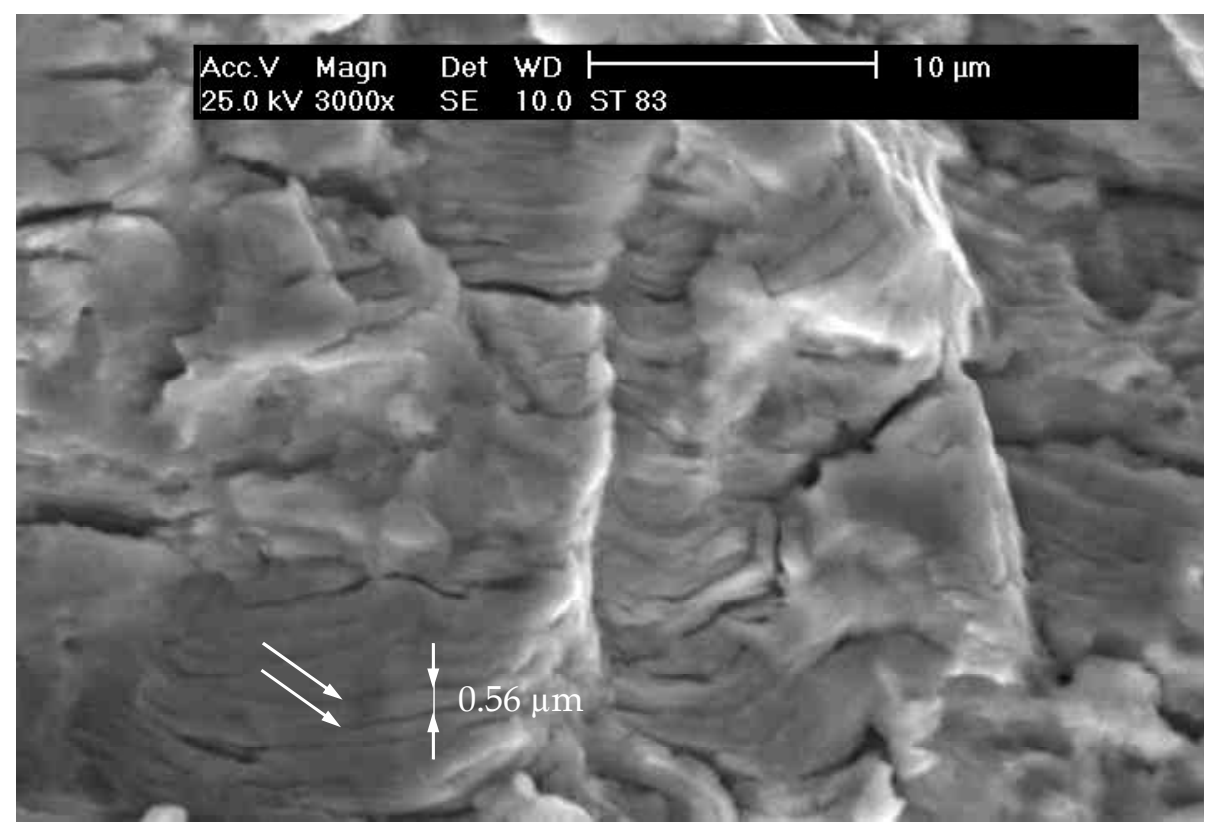

Figure 8: SEM micrograph of fatigue crack surface showing fatigue striations (magnification 3000x). 
In Figure 7 a SEM micrograph of this last location at a magnification of 750 times is shown. Two different regions, divided by the dotted line, can be clearly observed. The lower region is the brittle fracture surface. It has a faceted aspect of a cleavage fracture pattern caused by the brittle fracture of the pin that was forced after deep cooling. In the region above the dotted line striations can be observed, which are caused by fatigue fracture. A detailed view of the region inside the white rectangle in this figure is provided in Figure 8 which has a magnification of 3000 . Here the individual fatigue striations can be clearly distinguished (two striations are indicated by the white arrows). The crack propagation direction is perpendicular to the striations or upwards in the figure. The mean cyclic crack depth increase in this region is determined at $d a / d N=0.56 \mu \mathrm{m}$. The same procedure is used to determine the $d a / d N$ values at location 1 and 2. The total crack depth, measured as the distance between the thread root where the crack initiated and the pin inner wall, is $1.889 \mathrm{~mm}$.

Additionally, crack depth increases are measured in a second sample tested at the same stress amplitude of $S_{a}=90 \mathrm{MPa}$ and with a total fatigue life $N=19663$ cycles. The three measured locations in this additional sample are numbered in the same way as in the sample shown in Figure 6 . The measured $d a / d N$ and total crack depth values in both samples are summarized in Table 1. The fatigue crack growth behaviour of the small scale specimens is discussed further.

\begin{tabular}{|c|c|c|}
\hline Fatigue life $N$ & 35220 & 19663 \\
\hline Crack depth [mm] & 1.889 & 1.835 \\
\hline$d a / d N$ location $1[\mu \mathrm{m}]$ & 0.44 & 0.45 \\
\hline$d a / d N$ location $2[\mu \mathrm{m}]$ & 0.54 & 0.53 \\
\hline$d a / d N$ location $3[\mu \mathrm{m}]$ & 0.56 & 0.65 \\
\hline
\end{tabular}

Table 1: Cyclic crack depth increase values.

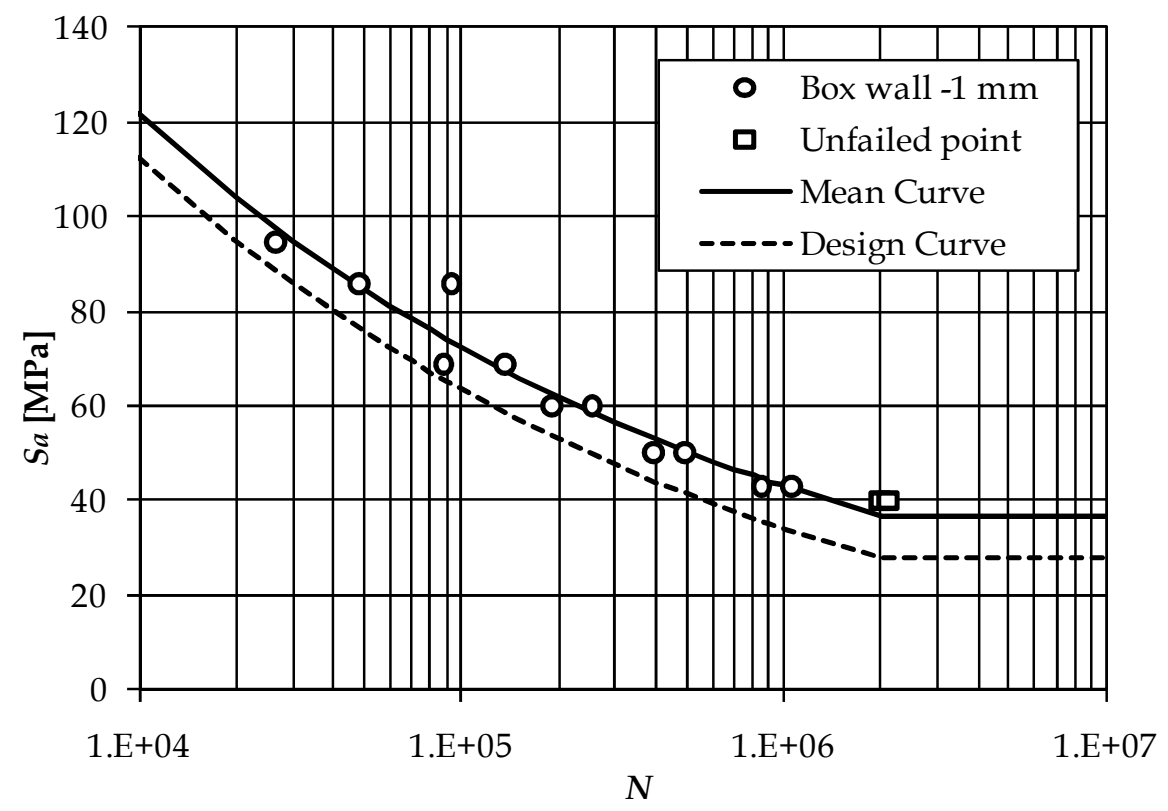

Figure 9: S-N curve for the 1" connection with box wall thickness reduction of $1 \mathrm{~mm}(R=0.1)$.

\subsection{Reduced box wall thickness $-1 \mathrm{~mm}$}

\subsubsection{S-N curve}

Thirteen tests are carried out on modified 1" API Line Pipe connections. The modification consists of a reduction in box wall thickness of $1 \mathrm{~mm}$ (coupling diameter $=38 \mathrm{~mm}$ ) as shown in Figure 1. Two of the specimens had not failed after 2 million cycles. The test results together with the mean and design curves corresponding to the data are shown in Figure 9. The mean curve has a standard deviation of $4.47 \mathrm{MPa}$ compared to the measured data and is described by the following relation.

$$
S_{a}=970.8 \cdot N^{-0.2256}
$$


When this mean curve is compared to the mean curve of the standard API Line Pipe connection, it is clear that the current modification exhibits an improved fatigue life. Hence, this is a first experimental confirmation of the idea that a box stiffness reduction can improve a connection's fatigue life (see [3]).

\subsubsection{Fracture surface}

The fracture surface of a fatigue test with a stress amplitude of $S_{a}=60 \mathrm{MPa}$ is shown in Figure 10. A leak appeared in the specimen after 253836 cycles. Again, SEM micrographs are used to determine the crack depth increase values at the three locations indicated in Figure 10. The SEM micrograph taken at the boundary between the fatigue and brittle fracture is given in Figure 11 and the resulting measured $d a / d N$ values are summarized in Table 2.

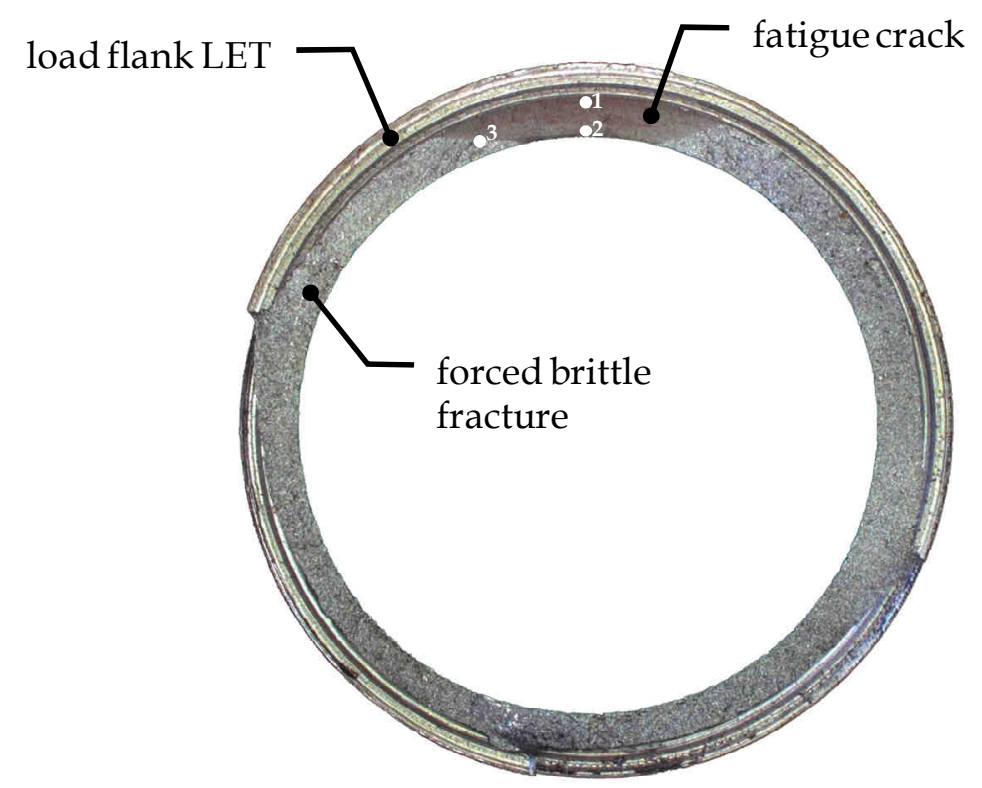

Figure 10: Fracture surface of a 1" API Line Pipe specimen with a box wall thickness reduction of $1 \mathrm{~mm}$.

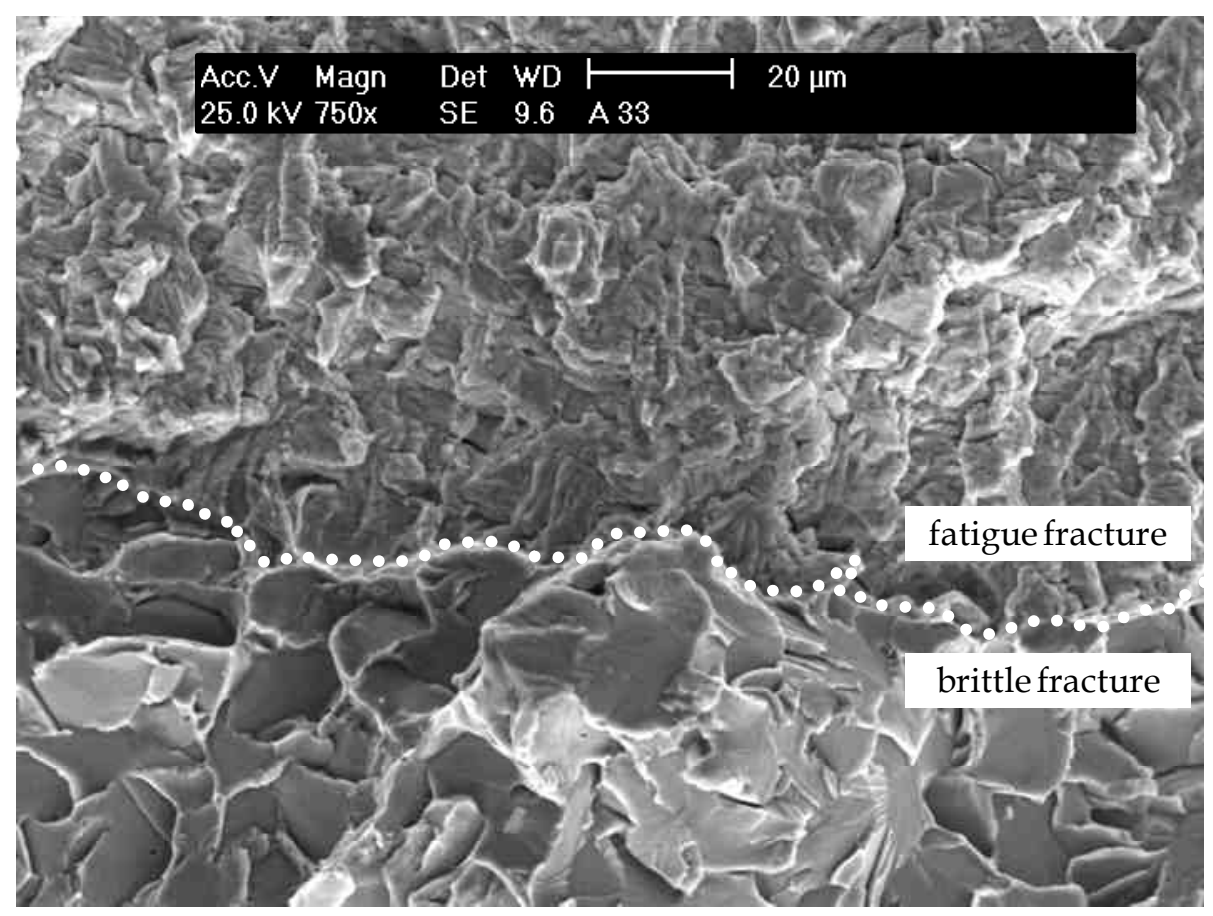

Figure 11: SEM micrograph of the boundary between the fatigue crack and the forced brittle fracture (magnification 750x). 


\begin{tabular}{|c|c|}
\hline Fatigue life $N$ & 253836 \\
\hline Crack depth [mm] & 1.812 \\
\hline$d a / d N$ location $1[\mu \mathrm{m}]$ & 0.40 \\
\hline$d a / d N$ location $2[\mu \mathrm{m}]$ & 0.48 \\
\hline$d a / d N$ location $3[\mu \mathrm{m}]$ & 0.48 \\
\hline
\end{tabular}

Table 2: Cyclic crack depth increase values.

\section{DISCUSSION}

\subsection{S-N curves}

In Figure 12 the results of the experimental cyclic bending tests are summarized. It can be seen that the standard API Line Pipe has the worst fatigue properties since the other S-N curves are laying above the standard API Line Pipe curve. Hence, it is experimentally shown that geometrical changes and changing the thread contact conditions, without altering the thread shape itself, can affect the connection's fatigue life. It can be seen that applying PTFE on the threads improves the fatigue life. This corresponds with the observations of Majzoobi et al. [5]. During their fatigue tests on different bolt-nut combinations, they clearly showed the beneficial effect of PTFE tape and stated that the exact influence is dependent of the used nut type. For standard metric nuts the effect is more important in the high-cycle fatigue region. The differences are explained by the observation that the PTFE tape can be eroded due to small sliding of the engaged threads. Hence, when this sliding appears, the beneficial effect of the PTFE tape is destroyed. This corresponds to the observed behaviour of the threaded pipe connections. At high applied loads, the PTFE tape does not improve the fatigue life, while at low stress amplitudes, a beneficial effect can be seen.

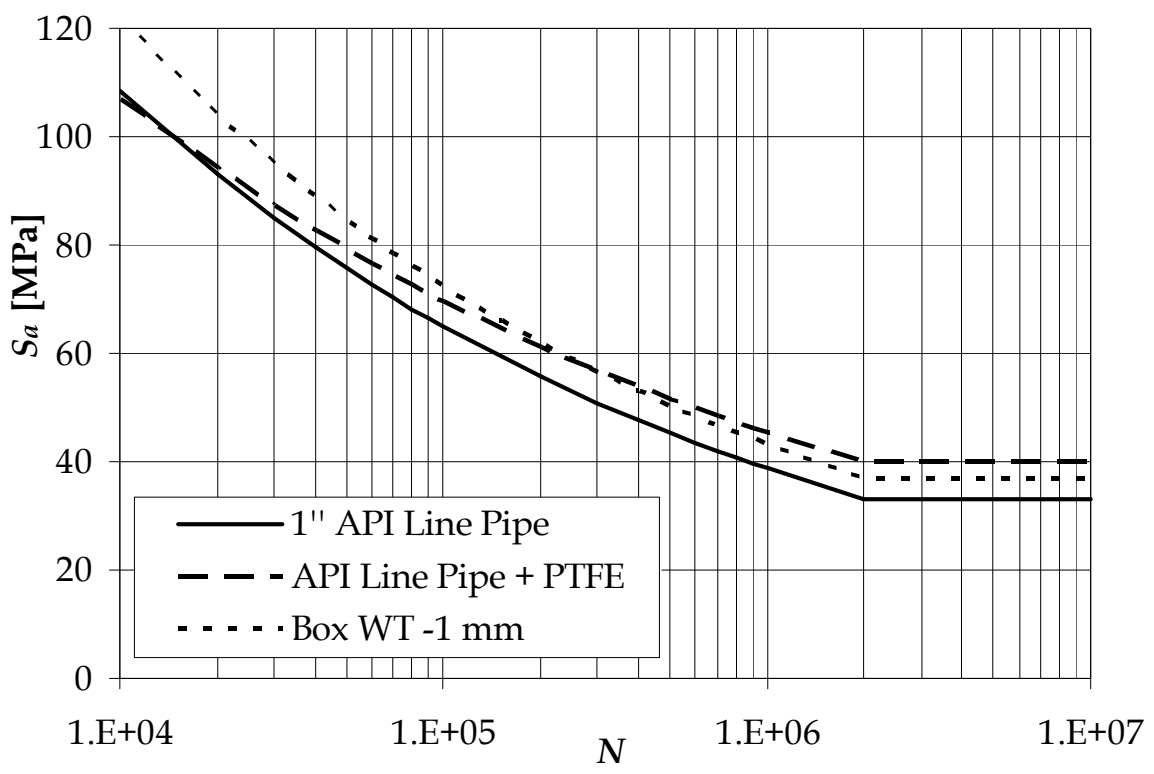

Figure 12: Comparison of the mean S-N curves.

\subsection{Fatigue crack propagation behaviour}

Using the crack depth increase values $d a / d N$ given in Table 1 and 2 an estimation can be made of the contribution of the crack propagation life $N_{p}$ to the total fatigue life $N$. For the three samples that are investigated using SEM, the applied stress amplitude, resulting fatigue life and the crack depth are given in Table 3. Additionally, the mean value of the crack depth increase $d a / d N$ is calculated with the crack depth increase at initiation measured at the thread root (location 1 in Figure 6 and 10) and at the end of propagation measured at the boundary between the fatigue fracture and brittle fracture region (location 3 ). The tabulated crack propagation lives are calculated by dividing the crack depth by the mean crack depth increase value. The total fatigue life $N$ is considered to be the sum of both the initiation life $N_{i}$ and propagation life $N_{p}$ as in Eq. (5), hence $N_{i}$ can also be determined.

$$
N=N_{i}+N_{p}
$$


Given the facts that this analysis is subjected to a certain amount of scatter (e.g. the difference in total fatigue life of the two discussed connections with PTFE tape) and that determination of the $d a / d N$ values is based on microscopic measurements, following conclusions can be made. From the results in Table 3 it can be seen that the mean $d a / d N$ value is larger when the total fatigue life is shorter. Since the total crack depth is constant within the tolerances of the connection, this results also in a shorter crack propagation life. Nevertheless, the contribution of the crack propagation life relative to the total connection's life is more important in case of lower values of $N$. When the total fatigue life is 253836 cycles, the crack propagation life takes less than $2 \%$ of the total life, while when $N=19663$ the crack propagation phase takes $17 \%$ of the fatigue life.

\begin{tabular}{|l|c|c|c|}
\hline Connection type & $\begin{array}{c}\text { API Line } \\
\text { Pipe + PTFE }\end{array}$ & $\begin{array}{c}\text { API Line } \\
\text { Pipe + PTFE }\end{array}$ & $\begin{array}{c}\text { Box wall } \\
-1 \mathrm{~mm}\end{array}$ \\
\hline Stress amplitude $\boldsymbol{S}_{\boldsymbol{a}}[\mathrm{MPa}]$ & 90 & 90 & 60 \\
\hline Total fatigue life $\boldsymbol{N}$ & 19663 & 35220 & 253836 \\
\hline Crack depth $\boldsymbol{a}[\mathbf{m m}]$ & 1.835 & 1.889 & 1.812 \\
\hline Mean value of $\boldsymbol{d a} / \boldsymbol{d} \boldsymbol{N}[\boldsymbol{\mu m}]$ & 0.55 & 0.50 & 0.44 \\
\hline Crack propagation life $\boldsymbol{N}_{\boldsymbol{p}}$ & 3336 & 3778 & 4118 \\
\hline Crack initiation life $\boldsymbol{N}_{\boldsymbol{i}}$ & 16327 & 31442 & 249718 \\
\hline $\boldsymbol{N}_{\boldsymbol{p}} / \boldsymbol{N}$ & 0.170 & 0.107 & 0.016 \\
\hline
\end{tabular}

Table 3: Crack propagation data.

\section{CONCLUSIONS}

In this paper the results of fatigue experiments of threaded pipe connections under cyclic bending are presented. It is shown that the fatigue life of a connection can be increased by changing the coupling's geometry or by applying PTFE tape between the threads.

The fatigue cracks initiated at the root of the last engaged thread of the pin and propagated over a wide segment of the circumference before penetrating the pin wall. The contribution of the crack propagation life to the total fatigue life varies between $1.6 \%$ and $17 \%$ where the higher percentage corresponds to higher applied stress amplitudes.

\section{NOMENCLATURE}

a crack depth

$\mathrm{mm}$

$N$ number of cycles to failure

$N_{i} \quad$ fatigue crack initiation life

$N_{p} \quad$ fatigue crack propagation life

$S_{a} \quad$ stress amplitude

$\mathrm{MPa}$

\section{ACKNOWLEDGEMENTS}

The authors would like to acknowledge the support of all the colleagues of the Laboratory Soete that contributed in any way to this research project. Next to this, the financial support of the BOF fund (B/04939) of the Ghent University and of the FWO Vlaanderen (3G022806) are gratefully acknowledged.

\section{REFERENCES}

[1] Van Wittenberghe, J., De Baets, P., De Waele, W., De Pauw, J., Ost, W., Bui, T.T., De Roeck, G., Fatigue investigation of threaded pipe connections, Proceedings of the Day of Research, 182-189, 2010.

[2] Van Wittenberghe, J., De Pauw, J., De Baets, P., De Waele, W., Experimental determination of the fatigue life of modified threaded pipe couplings, Procedia Engineering, 2(1), 1849-1858, 2010. 
[3] Van Wittenberghe, J., De Baets, P., De Waele, W., Timothy, G., Bui, T.T., De Roeck, G., Design characteristics that improve the fatigue life of threaded pipe connections, Sustainable Construction \& Design, 334-341, 2011.

[4] BS7608:1993, Code of practice for Fatigue Design and Assessment of Steel Structures, British Standards Institution, 1999.

[5] Majzoobi, G.H., Farrahi, G.H., Hardy, S.J., Pipelzadeh, M.K., Habibi, N., Experimental results and finiteelement predictions of the effect of nut geometry, washer and Teflon tape in the fatigue life of bolts, Fatigue and Facture of Engineering Materials, 28(6), 557-564, 2005. 